\title{
Treatment with acyclovir of genital herpes simplex virus infection complicated by eczema herpeticum
}

\author{
G E ROBINSON,* G S UNDERHILL,† G E FORSTER,* C KENNEDY,* AND \\ K MCLEAN* \\ From the *Praed Street Clinic and the + Department of Virology, St Mary's Hospital, London
}

SUMMARY Eczema herpeticum is a potentially serious disease that may be fatal. We report two cases of infection with genital herpes simplex virus (HSV) that were complicated by eczema herpeticum and were treated successfully with acyclovir.

\section{Introduction}

Eczema herpeticum, or Kaposi's varicelliform eruption due to herpes simplex virus (HSV), is an uncommon but well recognised disease. ${ }^{1}$ The aetiological agent is usually HSV type I, but infection with HSV type II has been reported. ${ }^{2}$ People with atopic eczema are most frequently affected, but it has been associated less commonly with other skin disorders, such as Darier's disease, pemphigus, and seborrhoeic eczema. ${ }^{1}$ The disease ranges from a mild transient disorder to a fulminant and fatal illness. The mortality is probably less than $10 \% \cdot{ }^{13}$ Eczema herpeticum is characterised clinically by a sudden fever and the development of vesicles that appear in crops. The lesions are usually found in dermatitic skin but in severe cases normal skin is also affected. The vesicles enlarge peripherally, develop central umbilication, and progress through pustular and crusted phases. Secondary bacterial infection is common. Death may result from systemic dissemination of the virus, or may follow septicaemia, shock, and disseminated intravascular coagulation.

Attempts to treat eczema herpeticum with various agents have been reported.-5 We report on two patients presenting with eczema herpeticum as a complication of first episode genital herpes who were treated with acyclovir.

\section{Case reports}

CASE 1

A 19 year old woman presented to this clinic with a seven day history of vulval soreness and ulceration.

Address for reprints: Dr G E Robinson, Department of Obstetrics and Gynaecology, The London Hospital, Whitechapel, London EC1

Accepted for publication 14 February 1984
In the preceding 48 hours she had noted crops of blisters on her neck, right shoulder, and left nipple. Four days before presentation she had suffered a severe headache with an associated stiff neck. She had no history of herpetic infection. Mild atopic eczema had been present since childhood. Her regular sexual partner had had a "cold sore" on his lower lip for six days.

On examination she looked ill, her temperature was $38^{\circ} \mathrm{C}$, and her throat was inflamed. Enlarged lymph nodes were palpable in the cervical and inguinal areas. Ulcerating herpetiform lesions were noted on the right side of her neck, her right shoulder, left nipple, and vulva. There was mild eczema and scarring of both wrists.

She was admitted to hospital and started receiving oral acyclovir $200 \mathrm{mg}$ five times daily for five days. HSV type I was cultured from all lesions. After treatment for 24 hours her temperature was normal. No further lesions appeared, and she was discharged home after 72 hours. All lesions had healed on review.

CASE 2

A 25 year old man presented to this clinic with a six day history of genital ulceration. In the past month he had noted a worsening of eczema and had felt generally unwell. He had suffered from severe atopic eczema since childhood, treating himself with betamethasone cream intermittently. There was no history of previous herpetic infection. He had a regular female sexual partner who was asymptomatic.

On examination he had enlarged preauricular and inguinal lymph nodes but was not feverish. He had severe excoriated eczema and scarring and lichenification on his trunk, arms, and legs. Both eyelids were cracked, the left upper eyelid showing herpetiform vesicles. There were extensive crusted herpetic lesions 
affecting the shaft of the penis and the prepuce and extending into his groins.

Because he had severe eczema, genital herpes, and his left eyelid was affected he was admitted to hospital. He was treated with intravenous acyclovir $(5 \mathrm{mg} / \mathrm{kg}$ ) for 24 hours followed by oral acyclovir $200 \mathrm{mg}$ five times daily for four days. Specimens from all lesions were cultured and HSV type I was isolated. An ophthalmic opinion was sought; the cornea was not affected, and 3\% acyclovir ointment was prescribed for his left eye. After 24 hours' treatment he felt constitutionally better. No new lesions formed. Secondary infection of the genital lesions with Staphylococcus aureus was treated with oral flucloxacillin. When he was discharged from hospital the herpetic lesions were crusting, and one week later they had healed without scar formation.

\section{Discussion}

Kaposi's varicelliform eruption was first described in 1887.6 It may be described as a secondary viral infection, and is seen most frequently as a complication of atopic dermatitis and keraotosis follicularis (Darier's disease). The principal causative virus is probably HSV, but vaccinia was responsible for a number of cases when vaccination against smallpox was routine. ${ }^{7}$ As $3 \%$ of the population have a history of atopic eczema and the reported incidence of genital HSV is increasing ${ }^{8}$ we expect the incidence of eczema herpeticum to rise. It is a potentially fatal condition and should therefore be treated aggressively to prevent the viscera being affected by viraemia and to control secondary bacterial infection.

Acyclovir is a potent antiviral agent that is effective against genital HSV in both intravenous ${ }^{9}$ and ora ${ }^{10}$ formulations by reducing viral shedding, the formation of new lesions, and pain. In our second patient it was administered intravenously to obtain maximum serum concentrations because the eye was threatened and the eczema herpeticum was severe. Both oral and intravenous formulations were effective in improving constitutional symptoms and healing lesions.

To our knowledge there are no published reports of genital infection with HSV complicated by eczema herpeticum having been treated with acyclovir. Although it is usually a complication of primary infection with HSV, eczema herpeticum does recur. ${ }^{1}$ We do not know if acyclovir would be effective in such recurrence.

We thank Drs J R W Harris and D Goldmeier for allowing us to review patients under their care.

\section{References}

1. Wheeler CE Jr, Abele DC. Eczema herpeticum, primary and recurrent. Arch Dermatol 1966;93:162-73.

2. Hazen PG. Eczema herpeticum caused by herpes simplex virus type 2. Arch Dermatol 1977;113:1085-6.

3. Swart RNG, Vermeer BJ, Van Der Meer JWM, Enschede FAJ, Verstag J. Treatment of eczema herpeticum with acyclovir. Arch Dermatol 1983; 119:13-6.

4. Chang TW, Weinstein L. Eczema herpeticum treatment with methylene blue and light. Arch Dermatol 1975;110;1174-5.

5. Braunstein BL, Greer KE. Treatment of eczema herpeticum with vidarabene. Arch Dermatol 1982; 118:597-8.

6. Kaposi M. Pathologie und therapie der hautkrankheiten. Berlin, 1887:483. Quoted in: Jablonski S. Illustrated dictionary of eponymic syndromes and diseases and of their synonyms. Philadelphia: WB Saunders, 1969.

7. Atherton DJ. Marshall WC. Eczema herpeticum. Practitioner 1982;226:971-3.

8. Anonymous. Sexually transmitted disease surveillance $1981 . \mathrm{Br}$ Med J 1983; 286: 1500-1.

9. Mindel A, Adler MW, Sutherland S, Fiddian A P. Intravenous acyclovir treatment for primary genital herpes. Lancet 1982; i:697-700.

10. Nilsen AE, Assen T, Halsos AM, et al. Efficacy of oral acyclovir in the treatment of initial and recurrent genital herpes. Lancet 1982; ii:571-3. 